\title{
Accurate Age Estimations from Dental Cementum and A Childbirth Indicator - A Pilot Study
}

\author{
Ristova $\mathrm{MM}^{1}$, Talevska $\mathrm{M}^{1,2}$ and Stojanovska $\mathrm{Z}^{3}$ \\ ${ }^{1}$ Institute of Physics, Faculty of Natural Sciences and Mathematics, Ss Cyril and Methodius University, Republic of \\ Macedonia \\ ${ }^{2}$ Forensic Department, Ministry of Internal Affairs, Bitola, Republic of Macedonia \\ ${ }^{3}$ Faculty of Medical Sciences, University Goce Delcev, Republic of Macedonia
}

${ }^{*}$ Corresponding author: Ristova MM, Professor, Institute of Physics, Faculty of Natural Sciences and Mathematics, Ss Cyril and Methodius University, Skopje, Republic of Macedonia, Tel: +389 71214 013, E-mail:mima.ristova@gmail.com

\section{Citation: Ristova MM, Talevska M, Stojanovska Z (2018) Accurate Age Estimations from Dental Cementum and a Childbirth Indicator - a Pilot Study. J Forensic Sci Criminol 6(1): 102}

Received Date: February 7, 2018 Accepted Date: July 5, 2018 Published Date: July 6, 2018

\begin{abstract}
This work is a pilot study that introduces an improved method for estimation of a chronological age of a human being using the incremental lines in a dental cementum. Scanning Electron Microscopy (SEM) images of longitudinal sections of the tooth roots were subject to SEM analysis. The protocol allows accurate age estimation even if the SEM images reveal a limited number of distinct incremental lines. Micrographs were analyzed with a calibrated thickness measuring tool, such as ImageJ. The study was based on fifteen freshly extracted teeth from adult males and females of a known age. An average cementum thickness $(C)$ and average incremental line thickness $(I L)$ was calculated for each chosen perpendicular level of the tooth root from the SEM image. The number of the incremental lines $\left(n_{\text {IL }}\right)$ was calculated from the ratio of the mean $C$ and $I L$, averaged across all levels. Finally, the estimated age is presented as a mean age from the data measured. The proposed protocol for age estimation represents a highly accurate (95\%), repeatable and reliable tool for estimation of the chronological age of an individual, using one single SEM scan. Also, from a single case study, we report that an anomalously thick incremental line occurred at the time position which could be related to a childbirth of that female individual. The method can serve forensic purposes.
\end{abstract}

Keywords: Biological age estimation; Incremental lines; Dental cementum; SE

\section{Introduction}

Forensic odontology is a forensic medicine discipline that serves the justice. It deals with the examination of evidence from the teeth [1], as the most resistant organ to degradation of all human remains. The tooth composition and structure endure severe changes of various conditions many years after one individual's death [2-4]. Furthermore, the teeth represent the unique structure, similar to the fingerprints. Thanks to these characteristics, the teeth can provide valuable information including identity, age, individual habits, professional occupation and, even a medical history of the individual. The dental evidence is crucial in the cases of mass destruction (war crimes or natural disasters).

The cementum embodies a mineralized (bone-like) tissue which covers the anatomical dental root. It comprises of $45-50 \%$ inorganic materials (hydroxyapatite), 50-55\% organic materials (collagen and non-collagen proteins, proteoglycans, glycoproteins, phosphoproteins) and water [5]. The cementum is deposited continuously throughout the life. It is rarely remodeled or adsorbed because of its nonvascular nature. It grows from a single mineralization front [6]. The thickness of the cementum varies at the different levels of the root cross-section, ranging from 15 to $200 \mu \mathrm{m}$ at the cervical section [6], or up to $600 \mu \mathrm{m}$ at the apical region of the root [7]. The cementum consists of characteristic lines of growth, also known as incremental lines, that could be viewed as either parallel lines to each other and to the surface of the root (longitudinal section), or concentric circles similar to the rings in trees (transversal section) [8,9].

In 1950 the cementum was first time mentioned as a tissue suitable for age assessment [10]. The reported technique was first used for age estimation of marine mammals [11]. The cyclic nature of the cementum growth could be associated with the seasonal changes implicating the metabolic rate of calcium. A pair of one dark and one bright stripe comprise one incremental line that corresponds to a period of one year of age $[12,13]$ and hence the name annulations. The cementum growth was found to depend 
on biomechanical forces, nutrition, and hormonal status [6]. A positive correlation between the real and calculated age was found in 1982 by Stott et al. Several authors described the cementum structure as dark, hyper-mineralized, so-called "rest lines" divided by brighter less mineralized translucent strips of rapid cementum growth [14]. The growth of the cementum tissue depends on the chemical process of synthesis [6].

The last two decades numerous authors examined the relationship between the quantitative characteristics of the cementum incremental lines with the age for forensic purposes. Different authors used teeth with different conditions. Some used the both, healthy and unhealthy teeth. Some authors reported results from transversal and some from longitudinal cross-sections of the tooth root, using various microscopic techniques, different models of analysis and counting the lines. Many of them found positive correlation, [2,15-20]. while others expressed skepticism about using this method [21-23].

Some authors reported results of the study of incremental lines using polarized light microscopy, which yielded better resolution (visualization) and better results in comparison to the regular light microscope [4]. Others, however, utilized phase-contrast microscopy [20]. However, the best results were achieved with Scanning Electron Microscopy (SEM) of the cementum crosssection images [24,25].

Herein we present the results of the pilot study of the incremental lines, using SEM as an imaging tool on 15 extracted teeth from individuals of a known age, gender and health condition of the tooth, to establish the correlation between the number of visible incremental lines $\left(n_{\mathrm{IL}}\right)$ in the cementum with the real age $\left(T_{r}\right)$ of an individual.

\section{Materials and Methods}

Fifteen freshly extracted teeth from 8 female and 7 male patients with a known age (ranging from 55 to 76 years) were used for this study. Information about the type of each extracted tooth, the age of its eruption $\left(T_{n}\right)$, the real age of the individual with an accuracy of 0.5 years $\left(T_{r}\right)$, gender (male-M or female-F), and the reason for extraction were recorded in (Table 1 ).

\begin{tabular}{|c|c|c|c|c|c|}
\hline $\begin{array}{c}\text { Sample } \\
\#\end{array}$ & Tooth & $\begin{array}{c}\text { Age of } \\
\text { eruption } T_{n}\end{array}$ & $\begin{array}{c}\text { Real Age } \\
T_{r}\end{array}$ & Gender & $\begin{array}{l}\text { Reason for } \\
\text { Extraction }\end{array}$ \\
\hline 1 & 33 - Canine & $9.5 \pm 0.5$ & 61.5 & M & Pulpitis \\
\hline 2 & 32 - Lateral Incisor & $7.5 \pm 0.5$ & 62.0 & M & Periodontitis \\
\hline 3 & 24 - First Premolar & $10.5 \pm 0.5$ & 64.0 & $\mathrm{~F}$ & $\begin{array}{l}\text { Progressive } \\
\text { caries }\end{array}$ \\
\hline 4 & 37 - Second Molar & $12.0 \pm 1.0$ & 68.0 & $\mathrm{~F}$ & Periodontitis \\
\hline 5 & 35-SecondPremolar & $11.5 \pm 0.5$ & 55.0 & $\mathrm{~F}$ & Periodontitis \\
\hline 6 & 34 - First premolar & $11.0 \pm 1.0$ & 55.0 & $\mathrm{~F}$ & Periodontitis \\
\hline 7 & 33 - Canine & $9.5 \pm 0.5$ & 73.0 & M & $\begin{array}{l}\text { Prosthetic } \\
\text { purposes }\end{array}$ \\
\hline 8 & 14 - First Premolar & $10.5 \pm 0.5$ & 64.5 & $\mathrm{~F}$ & $\begin{array}{l}\text { Prosthetic } \\
\text { purposes }\end{array}$ \\
\hline 9 & 43 - Canine & $9.5 \pm 0.5$ & 73.5 & $\mathrm{~F}$ & Periodontitis \\
\hline 10 & 42 - Lateral Incisor & $7.5 \pm 0.5$ & 76.0 & M & $\begin{array}{l}\text { Prosthetic } \\
\text { purposes }\end{array}$ \\
\hline 11 & 43 - Canine & $9.5 \pm 0.5$ & 72.0 & M & Periodontitis \\
\hline 12 & 43 - Canine & $9.5 \pm 0.5$ & 61.5 & F & $\begin{array}{l}\text { Progressive } \\
\text { caries }\end{array}$ \\
\hline 13 & 45 - Second Premolar & $11.5 \pm 0.5$ & 62.0 & M & Pulpitis \\
\hline 14 & 32 - Lateral Incisor & $7.5 \pm 0.5$ & 64.0 & $\mathrm{~F}$ & Periodontitis \\
\hline 15 & 15 - Second Premolar & $11.0 \pm 1.0$ & 68.0 & M & $\begin{array}{l}\text { Progressive } \\
\text { caries }\end{array}$ \\
\hline
\end{tabular}

Table 1: Type of the tooth, age, and gender of the patients

All tooth samples were stored in formalin until they were sterilized, both thermally, and by UV-irradiation. The crown of each tooth was then removed from the root. Longitudinal cross-sections were prepared with rotating dental tool - turbine (Sirona T3) with diamond burs. The surfaces were polished with a rubber tool. Three of the 15 samples $(\# 12,13,14)$ were banned from further analysis due to their fracture during the preparation since they were excessively brittle. After rinsing the samples with running water, the samples were spun dried and fixed to $\mathrm{Cu}$-sample holders, using a carbon paste. Scanning electron microscope (SEM) digitalized system, JEOL JSM-T220A SEM, was used as an imaging tool. Several images with different magnifications were obtained for each sample. Sample \#15 was also banned from further analysis, because of the absence of distinct incremental lines in the SEM-images. The best images of the samples \#1-11 were analyzed with ImageJ. The measuring tool was calibrated to the unit-length for each corresponding SEM image. Below we will show the methodology for the incremental line count we propose. 
Herein, a pair of one dark and one light band accounts for one incremental line. The thickness of the cementum layer (C) was measured from the SEM scans in Secondary Ions imaging mode, taken from the cervical parts of each tooth root longitudinal cross-section. The cementum thickness was measured as a near normal distance from the dentin-cementum junction to the root surface (cementum-vacuum or cementum-carbon paste junctions). As the cementum level varies along the tooth root, we propose a selection of at list two windows (denoted as levels on the images) to be marked in the SEM images. In the present example, the number of marked cementum levels in the SEM was three (as shown in Figure 1). The position of the cementum levels was chosen based on the presence of more than two array-elements of distinct and countable incremental lines within (the small windows of an improved contrast within the level in Figure 1). Furthermore, the cementum level should be sufficiently small in height, so that the cementum thickness does not change drastically within. As could be seen from Fig. 3, the cement thickness was measured three times $\left(C_{1}\right.$ - in the upper part, $C_{2}$ - at the medial part, and $C_{3}$ at the lower part of within each selected level (either Level I, II or III).

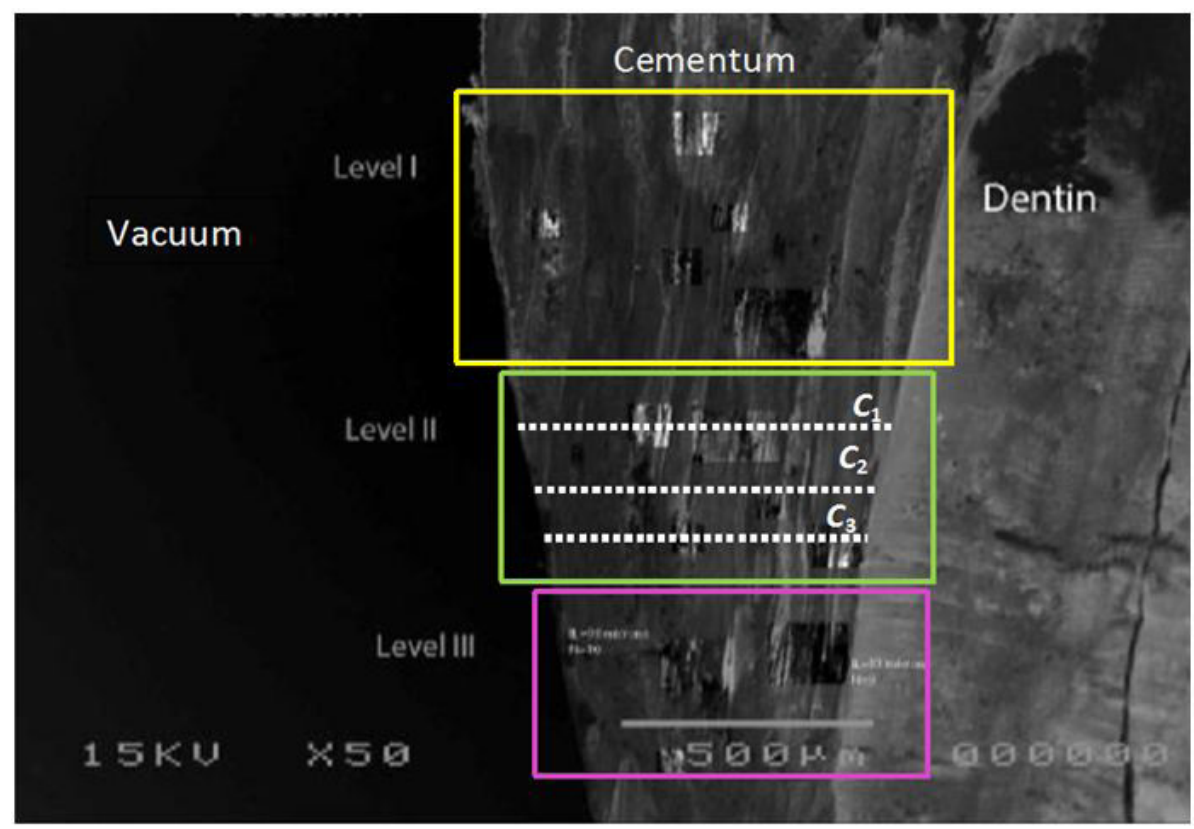

Figare 1a: Sample SEM-image analysis on a longitudinal section of tooth \#11: Margins of the Cementum are well defined between the vacuum or the carbon paste (on the left) and dentin (on the right). Levels ( widows) I, II and III were defined within the three rectangular markers. Cementum thicknesses at each level was evaluated as a mean of the three measures $\left(C_{1}, C_{2}\right.$, and $\left.C_{3}\right)$. The rectangular sections of an improved contrast allocate the countable and measurable arrays of incremental lines. The incremental lines count is shown at Level III

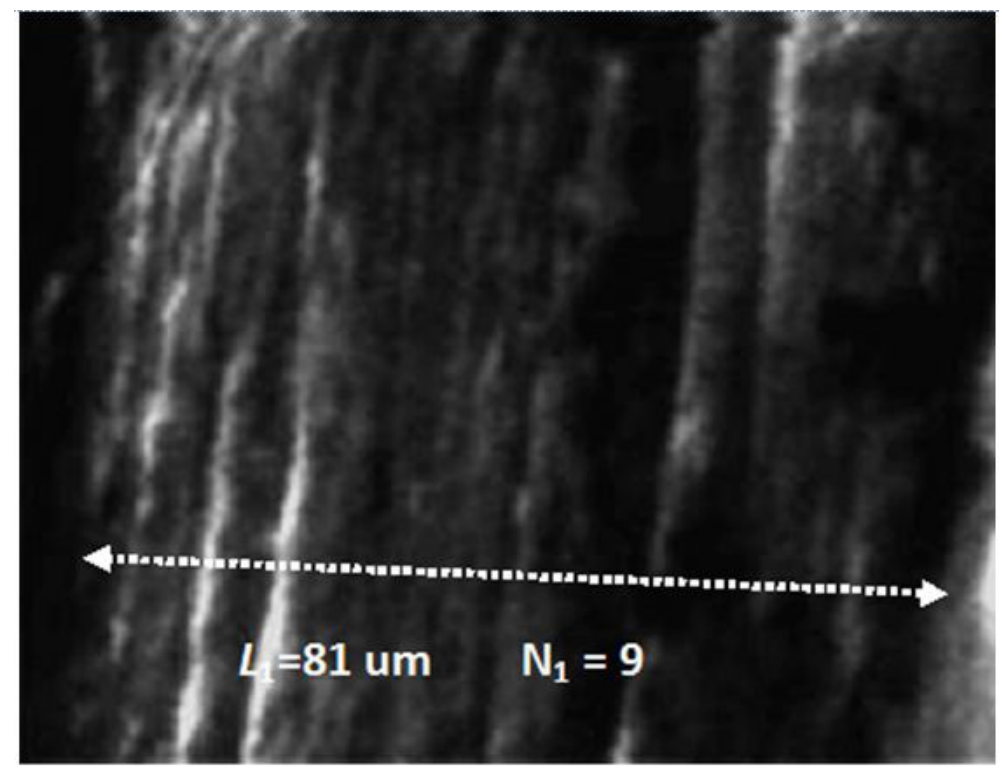

Figare 1b: Example array-element (rectangular section from Level III of Figure 1a) for determination of a length of the entire incremental line-array ( $L_{i}$ measurement), and incremental lines count $\left(n_{i}\right)$, in order to calculate the thickness of a single incremental line $\left(\mathrm{IL}=L_{1} / N_{1}=81 \mathrm{~nm} / 9=9 \mathrm{~nm}\right)$ 
For each designated level ( I, II, and III on Figure 1a) we have calculated the arithmetic mean cementum width. For instance, the cementum thickness at Level II was calculated as:

$$
\mathrm{C}_{\mathrm{II}}=\left(\mathrm{C}_{1}+\mathrm{C}_{2}+\mathrm{C}_{3}\right) / 3
$$

As was mentioned before, we have allocated the countable array-elements of incremental lines. The occurrence of such arrays is presented as rectangular areas of an improved contrast/brightness. After the image enhancement, we have measured each arrayelements near-normal lengths $\left(L_{i}\right)$ and recorded the corresponding incremental lines count $\left(N_{i}\right)$, as shown in (Figure 1b). The thickness of a single incremental line at the cementum level II $\left(I L_{I I}\right)$ was calculated as the arithmetic mean from all the ratios of the measured array-element length, $L_{i}$, and their corresponding incremental line-count $N$, using the following equation:

$$
I L_{\text {Level }}=\frac{\sum_{i=1}^{n} \frac{L_{i}}{N_{i}}}{n}
$$

For instance, at Level II from (Figure 1) we emphasize n=5 rectangular sections with distinct and "readable" incremental linearrays. After measuring each array-elements length $\left(L_{i}\right)$ and counting the corresponding number of incremental lines within $\left(N_{i}\right)$ the incremental line thickness at the first level was hence calculated by:

$$
I L_{I I}=\frac{\sum_{i=1}^{5} \frac{L_{i}}{N_{i}}}{5}
$$

It should be noted that we have also encountered SEM scans with only one single readable incremental array-element. Furthermore, the arithmetic mean of cementum thickness from all levels (presently three) $\left.\left(C=\left(C_{I}+C_{I I}+C_{I I I}\right) / 3\right)\right)$ was divided by the mean incremental line thickness $(I L)$, also calculated form all the three levels (in the present example $I L=\left(I L_{I}+I L_{I I}+I L_{I I I}\right) / 3$, and yielded the estimated number of incremental lines count:

$$
n_{I L}=\frac{C}{I L}
$$

Finally, to estimate the age $\left(T_{e}\right)$ of an individual, one should add the mean age at which the corresponding tooth erupts ( $\left.T_{n}\right)$ [28] to the calculated incremental line number $n_{I L}$ from Eq. 3, as follows:

$$
T_{e}=n_{I L}+T_{n}
$$

It should be noted that many potential challenges may occur during the 'reading' the SEMs. Some of the samples, for instance, showed morphological changes in the cementum boundaries with the dentin, making it difficult to measure the cementum width. Also, there were cracks in the cementum in some samples. Furthermore, the incremental line thickness is variable along the cementum 'timeline'. Moreover, there were SEM images of samples with indistinct/unreadable incremental lines, also lines that diverge from linear, as well as regions of curly, wavy, or even unclear, randomly shaped and chaotic in appearance. Some lines even overlapped or crossed over each other. Also, it should be noted that 4 out of 15 samples (27\%) were excluded from the study.

Also, it is noteworthy that over $50 \%$ of the tooth samples were affected by periodontitis. Nevertheless, the proposed method yielded results that allowed accurate age estimation of an individual.

\section{Results}

Selected SEM scans of the tooth samples, subject to this study, are represented in (Figure 2). From the SEMs below it is evident that the cementum thickness, morphology with the incremental line's structure vividly varies among the individuals. Some samples reveal incremental lines which are parallel, while as others illustrate irregular geometry. In addition, some samples show either morphological or mechanical defects across the cementum thickness, such as thickened lines or cracks. In our calculations of this study, all such defects were taken into consideration for the accurate cementum thickness $(C)$ evaluation. For instance, the width of a crack was deducted from the cementum thickness, in order to obtain the closest measure of $C$. 


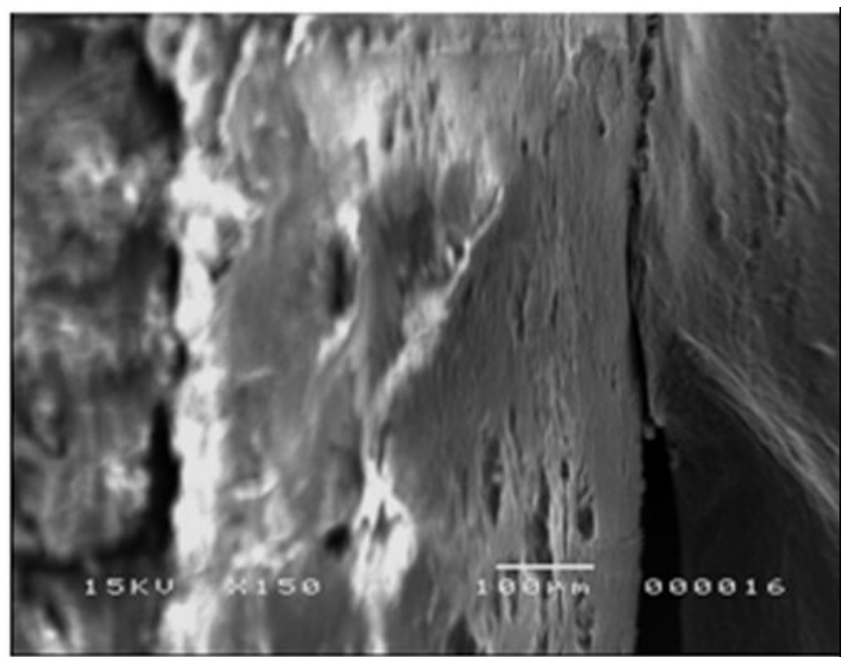

\#1 Whole cementum: morphology with small cavities

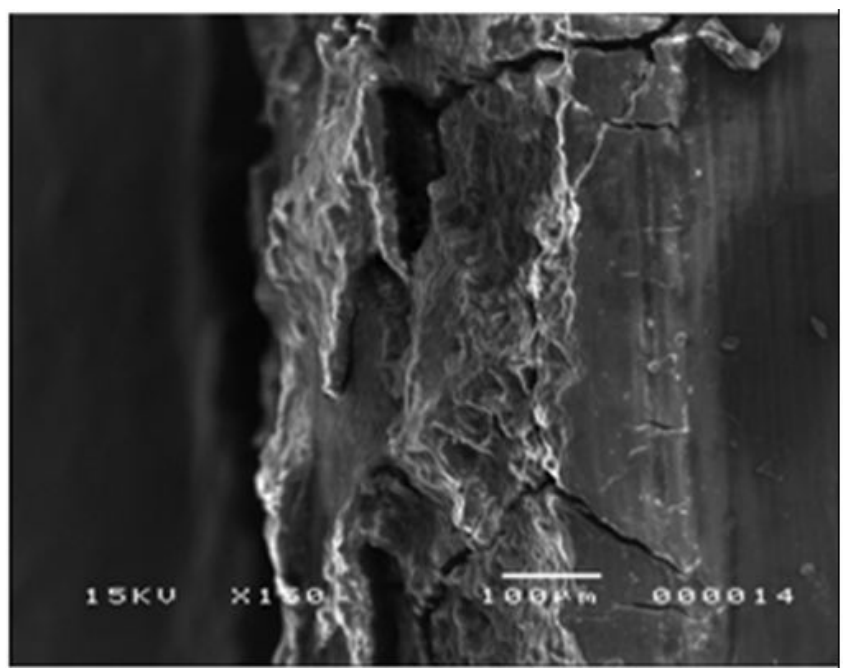

\#2 Whole cementum: porous morphology with large cavities

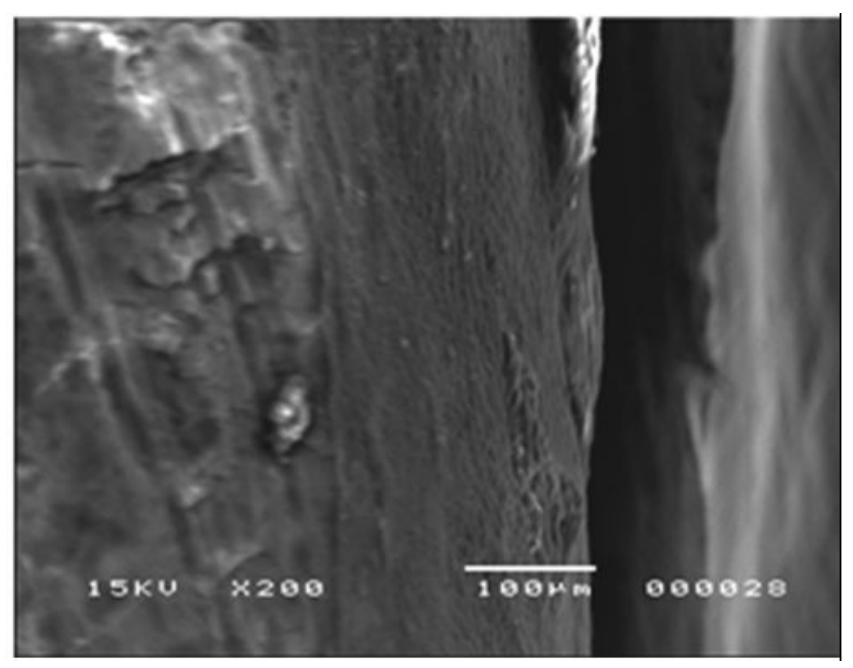

\#3 Whole cementum: homogenous and compact structure

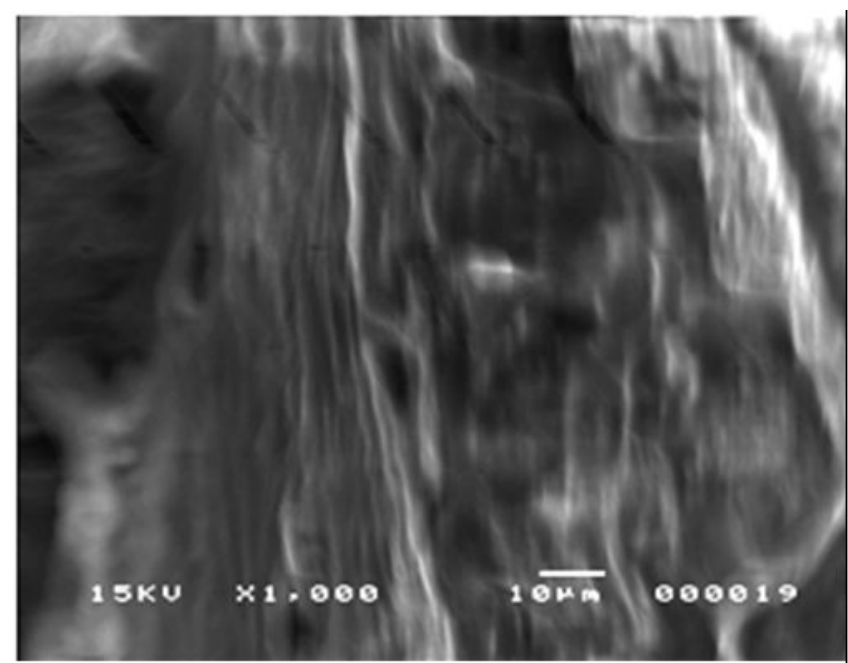

\#1 Detail of distinct incremental line array (left) and chaotic lines (right)

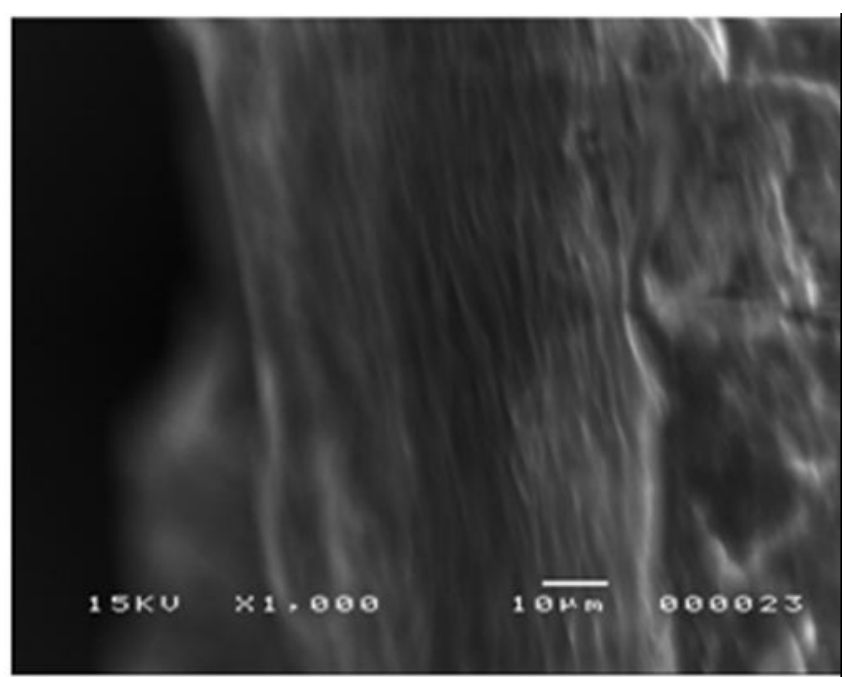

\#2 Detail of distinct incremental line array

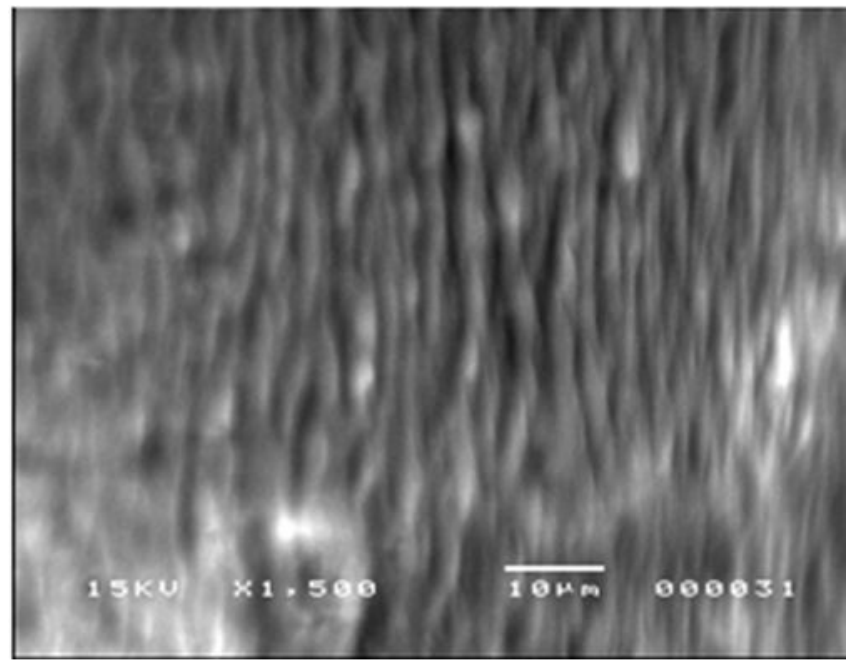

\#3 Detail of distinct incremental line arrays 


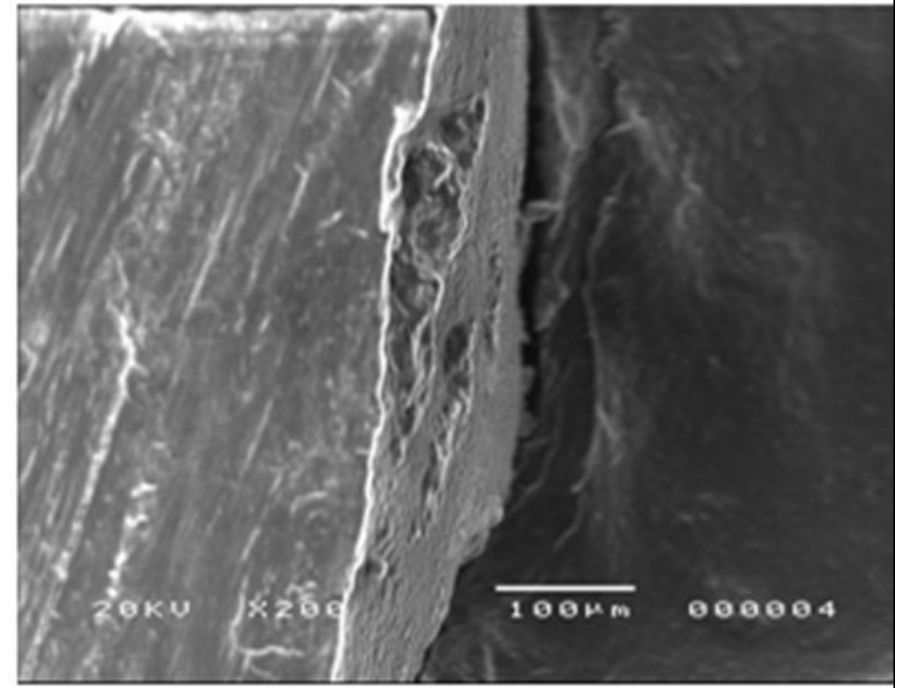

\#4 Whole cementum: thin irregular cementum: thickness of the cavities was deducted from the C-measurement

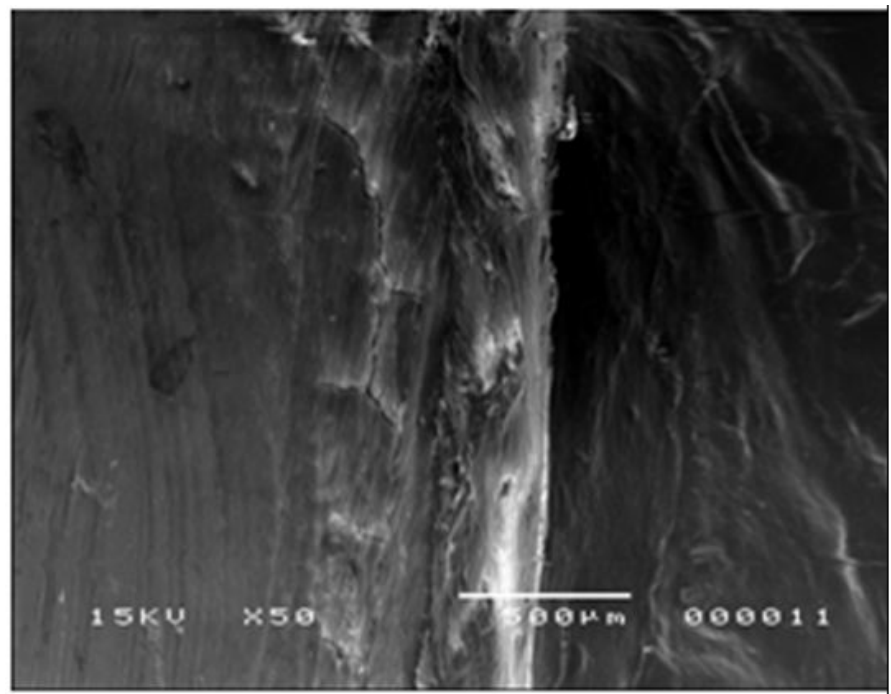

\#5 Whole cementum: well defined boundary betveen the cementum and dentin.

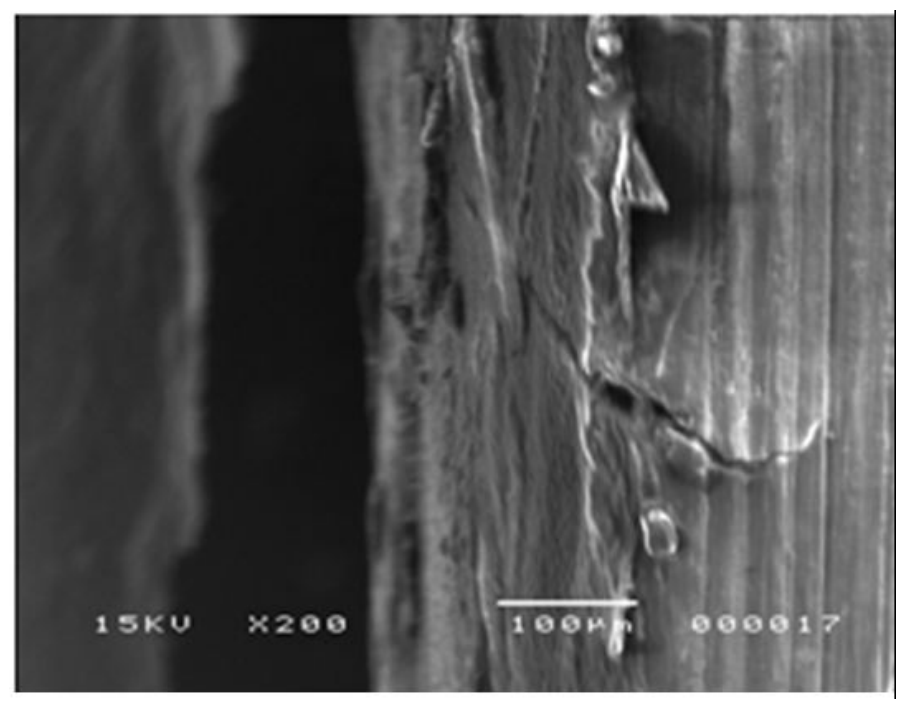

\#6 Whole cementum

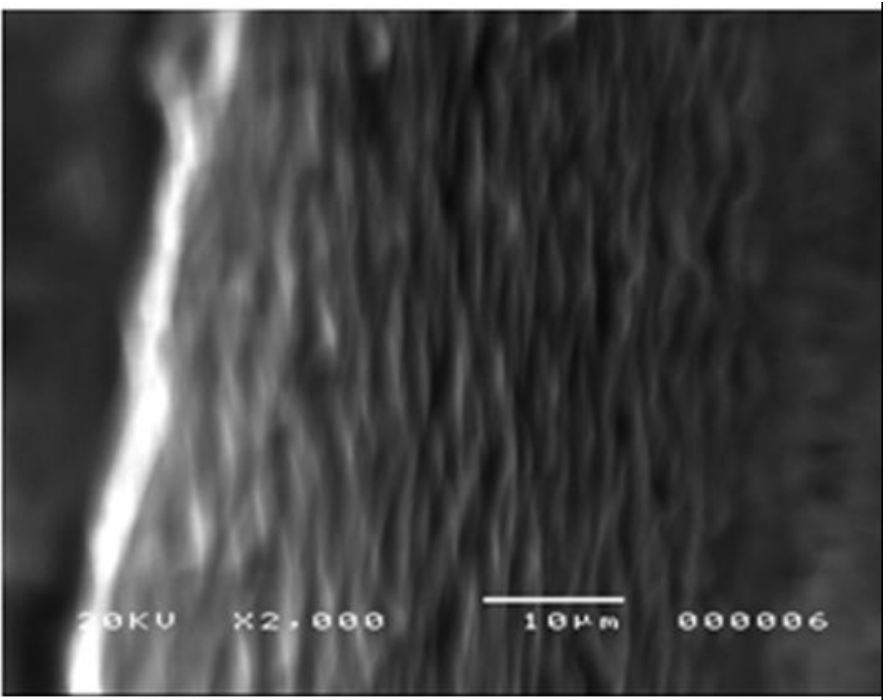

\#4 Detail of distinct incremental line array

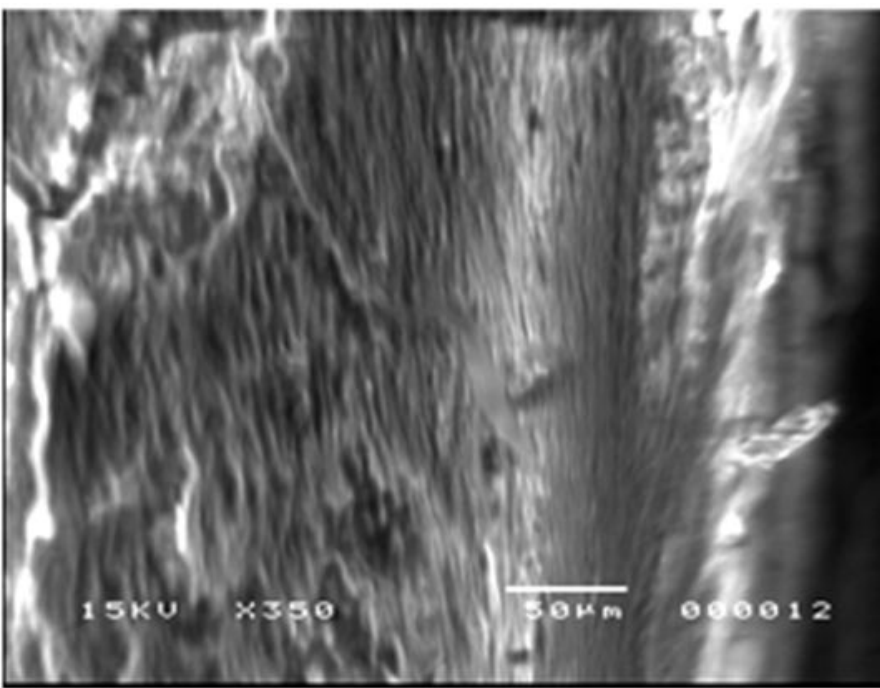

\#5 Detail of distinct incremental line arrays: (left) thicker (right) thinner incremental lines.

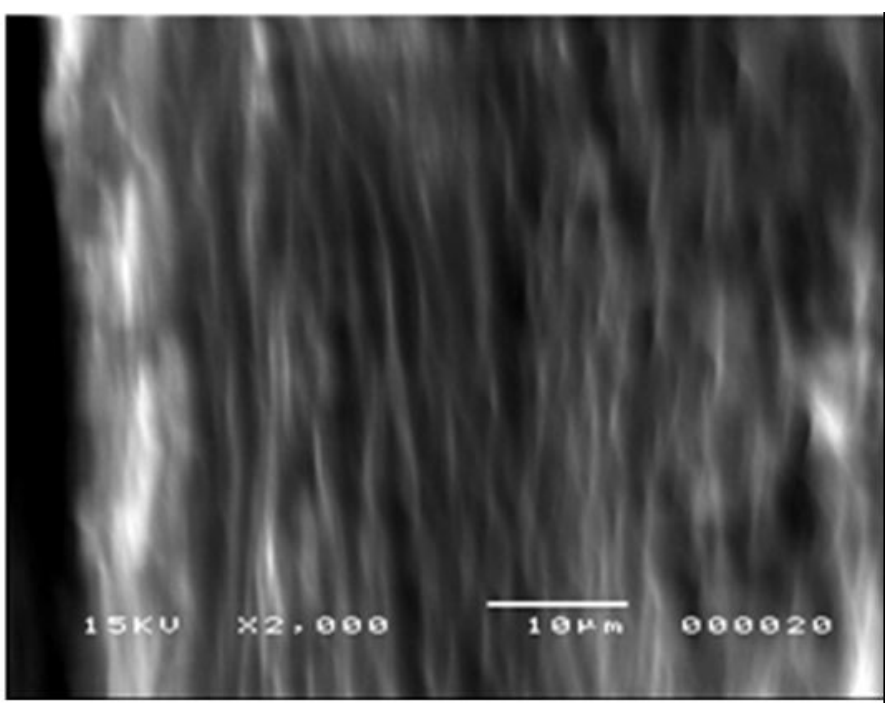

\#6 Detail of distinct incremental line arrays 

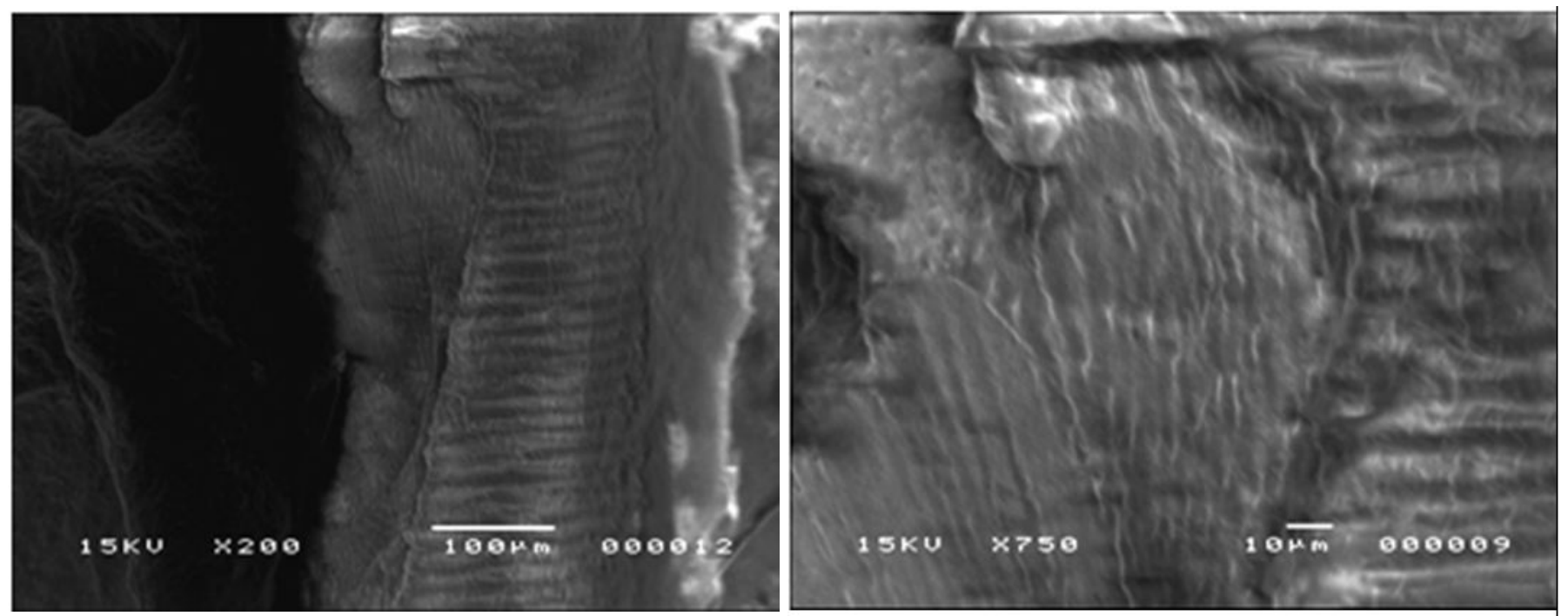

\#7 Whole cementum: visible sections of different cementum growth morhology

\#7 Detail of distinct incremental line arrays: variety of incremental line morphology

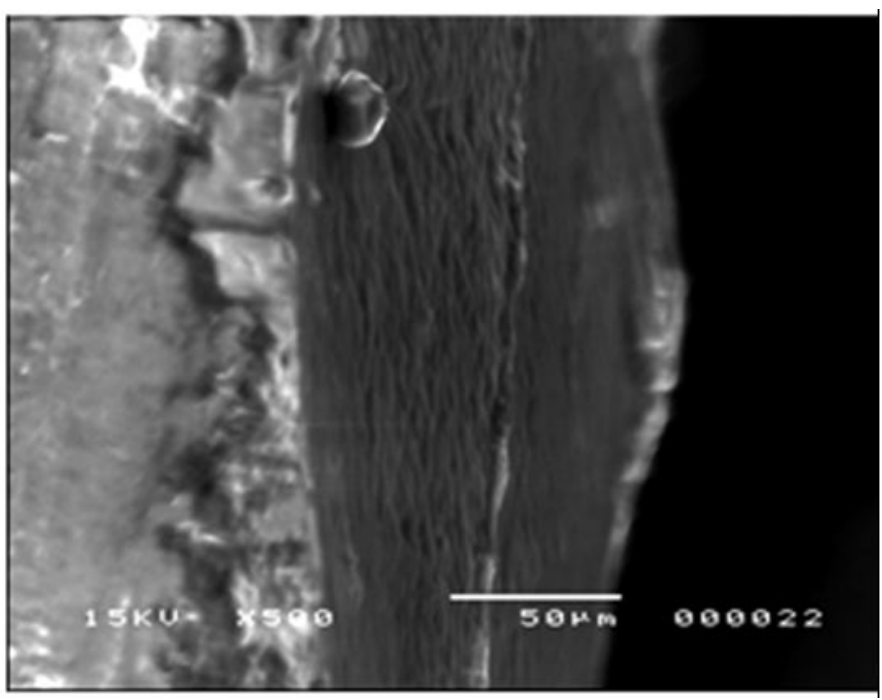

\#8 Whole cementum. The occurrence of one single anomalous incremental line at age 32 .

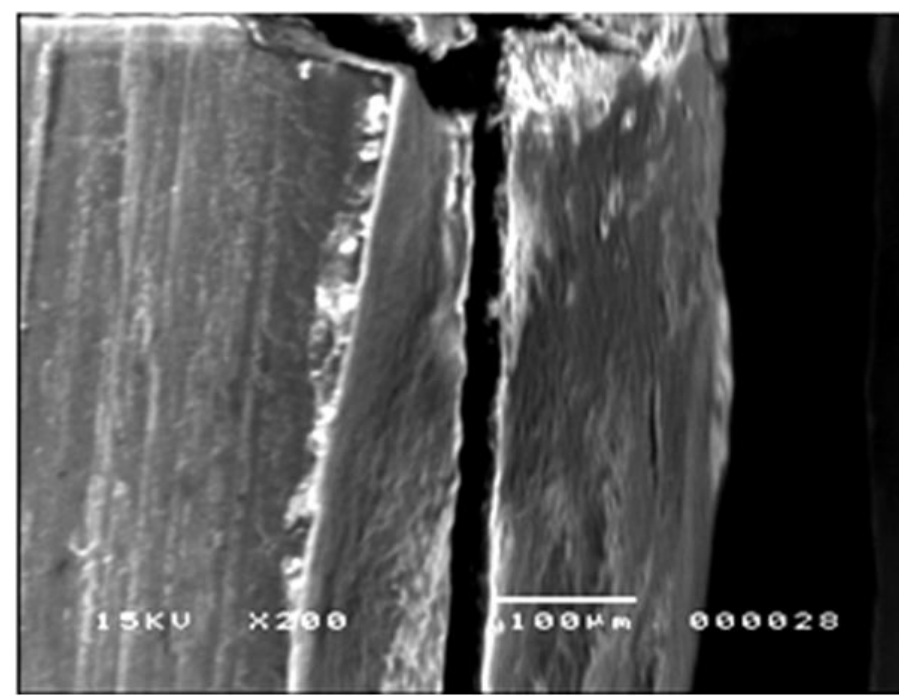

\#9 Whole cementum: the thickness of the crack in the cementum was deducted from C-measurement.

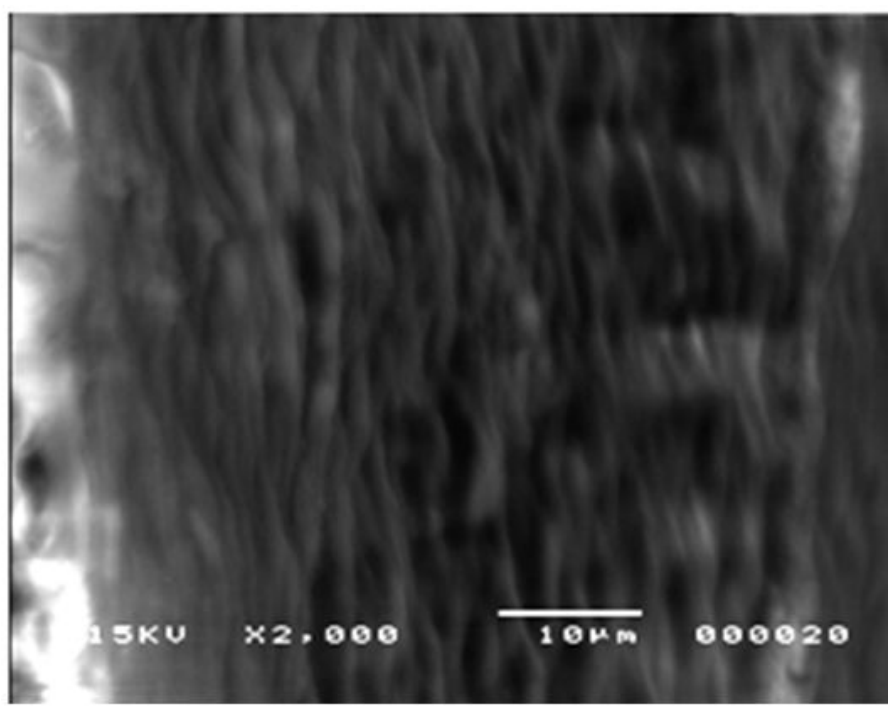

\#8 Detail of distinct incremental line arrays.

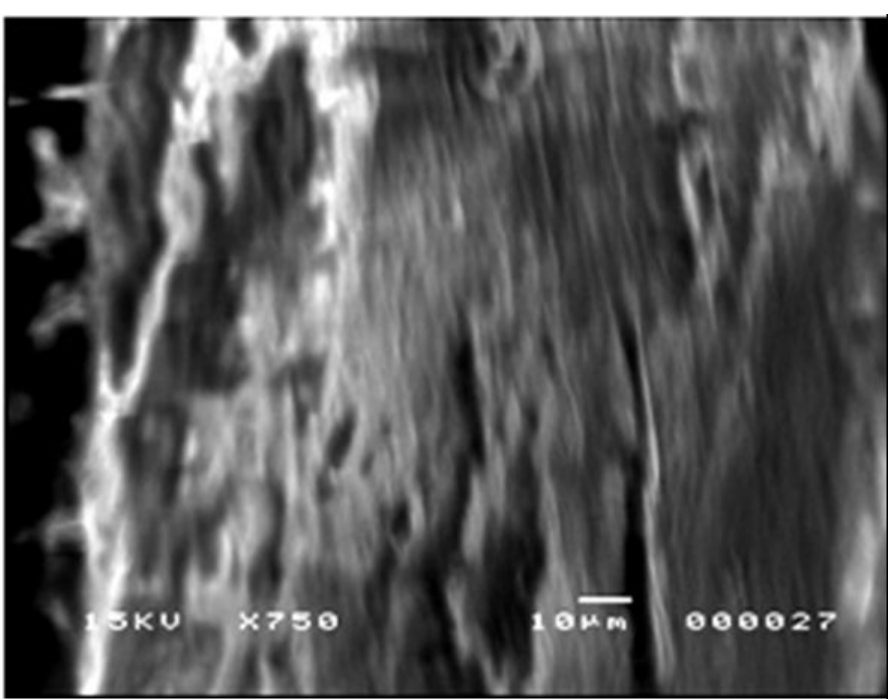

\#9 Detail of distinct incremental line arrays 


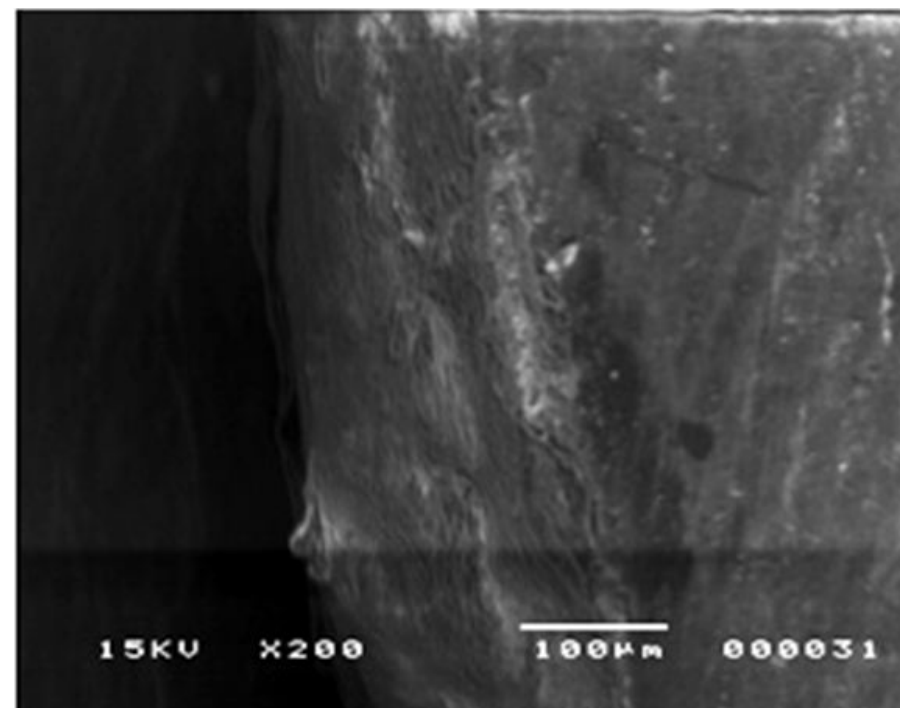

\#10 Whole cementum: diffuse boundary between the cementum and dentin.

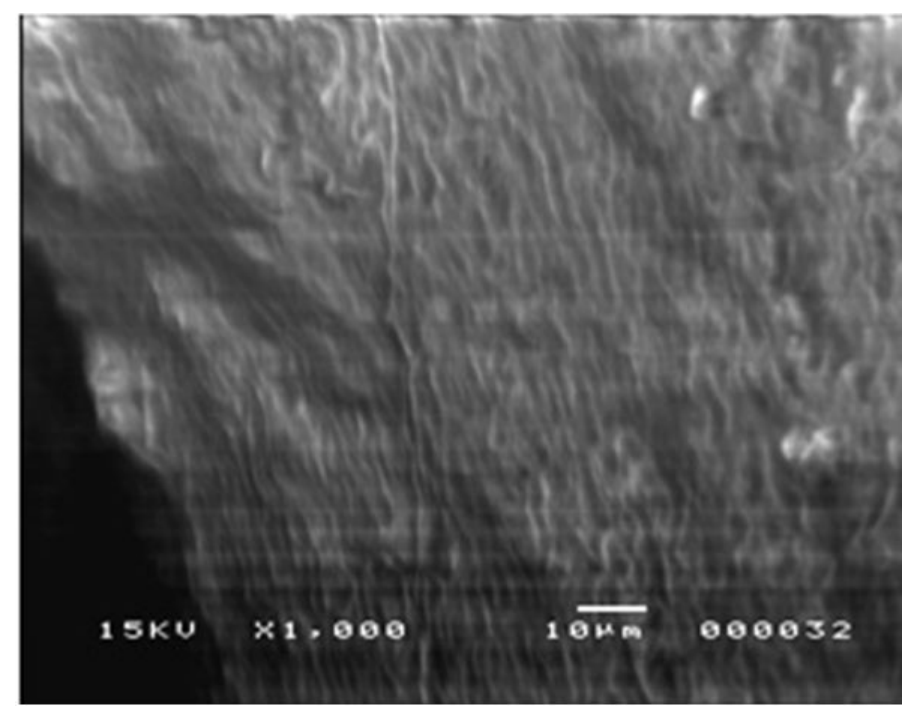

\#10 Detail of distinct incremental line arrays

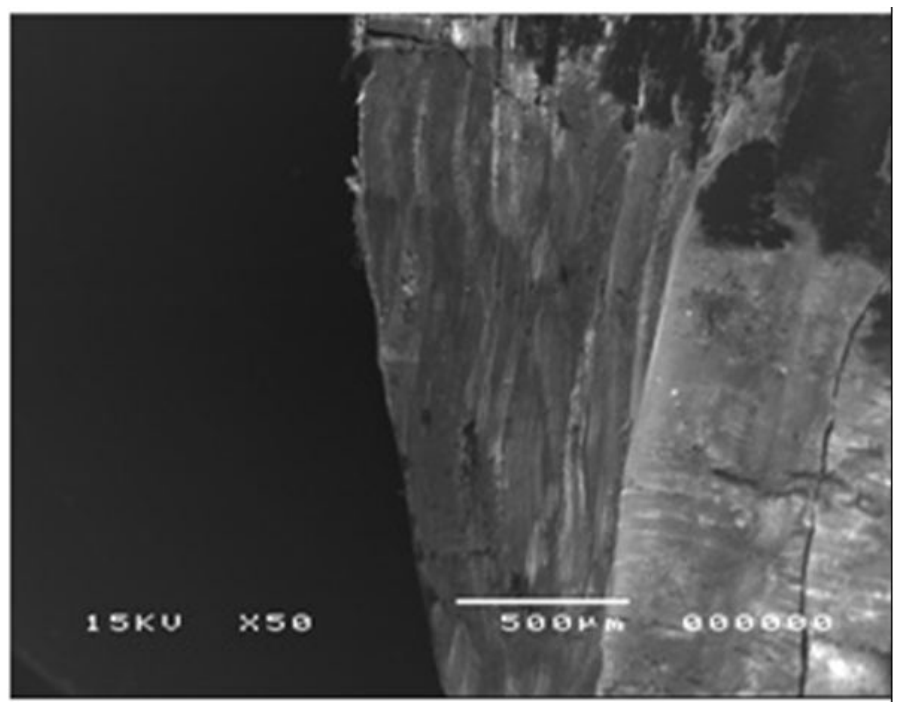

\#11 Whole cementum: C increases from 500 to $\sim 700 \mathrm{~nm}$

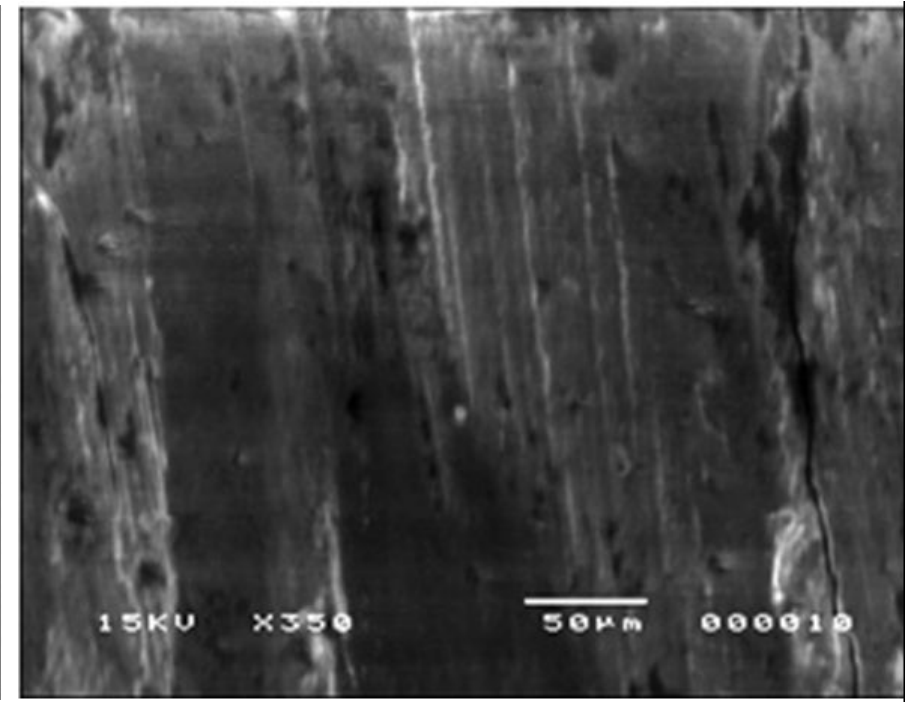

\#11 Detail of distinct incremental line arrays: regular parallel lines

Figare 2: SEM images of tooth samples \#1-11 (longitudinal sections): left images - SEMs revealing entire cement thickness; right images - SEMs revealing cementum morphology with distinct incremental line arrays (zoom into the corresponding left scan)

Table 2 contains the results of SEM image analysis of 11 teeth samples that were acquired from one single SEM scan of each tooth sample $(\mathrm{F} 1)$. The values of the mean cementum $(C)$, the mean incremental line thickness (IL) were obtained from the measurements at different levels $(k=2-4)$, using Eq. 2., Also, Table 2 shows the uncertainties in the cementum thickness $u(C)$ and the incremental line thickness $u(I L)$, calculated as standard uncertainties obtained from the repeated measurements (refer to the multiple rectangular sections with distinct incremental line arrays depicted in Figure 1). In order to show the interval of variations of the measured values, the corresponding minima and maxima were also given. The last three columns of Table 2 show the calculated number of incremental lines (nIL) for each tooth sample, using Eq. 3. The absolute and relative uncertainties of the estimated incremental line number, $u\left(n_{I L}\right)$ and $u\left(n_{I L}\right) \%$, were calculated from the standard combined uncertainties of the uncertainties of $C$ and $I L$, applying the law of uncertainty propagation.

In order to check the reproducibility of the estimation method, the same measuring and counting procedure was repeated by a second 'reader' who took a "second" SEM image (F2) of several tooth samples. The results of this limited Round Robin Study are given in Table 3. 


\begin{tabular}{|c|c|c|c|c|c|c|c|c|c|c|c|c|c|c|}
\hline$\#$ & $K$ & $\mathbf{n}$ & $\mathbf{N}$ & $\begin{array}{c}\mathbf{C} \\
(\mu \mathrm{m})\end{array}$ & $\begin{array}{c}\mathbf{u}(\mathbf{C}) \\
(\boldsymbol{\mu m})\end{array}$ & $\begin{array}{c}\mathbf{C m i n} \\
(\boldsymbol{\mu m})\end{array}$ & $\begin{array}{c}\mathbf{C m a x} \\
(\boldsymbol{\mu m})\end{array}$ & $\begin{array}{c}I L \\
(\mu \mathrm{m})\end{array}$ & $\begin{array}{c}\boldsymbol{u}(\mathbf{I L}) \\
(\boldsymbol{\mu m})\end{array}$ & $\begin{array}{c}I L- \\
\mathbf{m i n} \\
(\mu \mathrm{m})\end{array}$ & $\begin{array}{c}I L- \\
m a x \\
(\mu \mathrm{m})\end{array}$ & $\begin{array}{c}\boldsymbol{n}_{\mathrm{I}} \\
\boldsymbol{L}\end{array}$ & $\boldsymbol{U}$ & $u \%$ \\
\hline 1 & 3 & 4 & 17 & 347 & 9 & 326 & 370 & 7.1 & 0.3 & 5.8 & 8.7 & 49 & 2 & $5 \%$ \\
\hline 2 & 2 & 4 & 12 & 286 & 2 & 285 & 289 & 5.3 & 0.4 & 3.8 & 7.6 & 54 & 4 & $8 \%$ \\
\hline 3 & 3 & 5 & 27 & 202 & 5 & 191 & 213 & 4.0 & 0.2 & 2.1 & 7.1 & 51 & 3 & $6 \%$ \\
\hline 4 & 4 & 3 & 27 & 59 & 2 & 51 & 66 & 1.1 & 0.1 & 0.8 & 1.7 & 55 & 4 & $7 \%$ \\
\hline 5 & 3 & 4 & 33 & 308 & 2 & 302 & 14 & 7.0 & 0.4 & 3.3 & 0.4 & 44 & 2 & $5 \%$ \\
\hline 6 & 3 & 6 & 15 & 185 & 1 & 183 & 188 & 4.2 & 0.3 & 2.6 & 5.7 & 44 & 3 & $6 \%$ \\
\hline 7 & 2 & 5 & 21 & 306 & 2 & 273 & 364 & 4.7 & 0.2 & 3.5 & 6.2 & 65 & 3 & $5 \%$ \\
\hline 8 & 3 & 4 & 33 & 89 & 3 & 81 & 95 & 1.7 & 0.1 & 0.9 & 2.5 & 53 & 3 & $6 \%$ \\
\hline 9 & 4 & 8 & 47 & 240 & 6 & 213 & 268 & 3.8 & 0.1 & 2.1 & 4.9 & 64 & 2 & $4 \%$ \\
\hline 10 & 4 & 1 & 73 & 149 & 9 & 121 & 185 & 2.1 & 0.1 & 1.2 & 3.3 & 69 & 5 & $7 \%$ \\
\hline 11 & 3 & 1 & 53 & 652 & 36 & 575 & 735 & 9.9 & 0.7 & 5.8 & 14.5 & 66 & 6 & $9 \%$ \\
\hline
\end{tabular}

Table 2: Results of the measured mean cementum thickness $(C)$, mean incremental line thickness $(I L)$ and estimated number of incremental lines $\left(n_{I I}\right) \cdot \mathrm{k}$ is a number of the selected cementum levels $(2,3$ or 4$)$ from one single SEM image for each sample (F1). 1 is the total number of incremental line arrays at all levels, $\Sigma N$ is a sum of incremental line-count from all readable arrays at all examined root levels Figure 1

\begin{tabular}{|c|c|c|c|c|c|c|c|c|c|c|c|c|c|c|}
\hline \# & $K$ & $n$ & $\Sigma N$ & $\begin{array}{c}C \\
(\mu \mathrm{m})\end{array}$ & $\begin{array}{l}u(C) \\
(\mu \mathrm{m})\end{array}$ & $\begin{array}{l}C \min \\
(\mu \mathrm{m})\end{array}$ & $\begin{array}{c}C \max \\
(\mu \mathrm{m})\end{array}$ & $\begin{array}{c}I L \\
(\mu \mathrm{m})\end{array}$ & $\begin{array}{c}u(\mathrm{IL}) \\
(\mu \mathrm{m})\end{array}$ & $\begin{array}{l}I L- \\
\text { min } \\
(\mu \mathrm{m})\end{array}$ & $\begin{array}{l}I L- \\
\max \\
(\mu \mathrm{m})\end{array}$ & $\begin{array}{l}n_{I} \\
\mathrm{~L}\end{array}$ & $\begin{array}{c}u \\
\left(n_{\mathrm{IL}}\right)\end{array}$ & $\underset{\left(n_{\mathrm{IL}}\right)}{\mathrm{U}} \%$ \\
\hline 2 & 2 & 5 & 15 & 268 & 3 & 265 & 272 & 5.1 & 0.3 & 2.9 & 7.6 & 53 & 3 & 6 \\
\hline 4 & 2 & 4 & 24 & 91 & 3 & 83 & 98 & 1.6 & 0.1 & 0.8 & 2.5 & 57 & 4 & 7 \\
\hline 7 & 2 & 4 & 12 & 291 & 3 & 288 & 296 & 4.6 & 0.2 & 2.9 & 6.4 & 64 & 3 & 4 \\
\hline 8 & 3 & 6 & 47 & 69 & 1 & 66 & 72 & 1.2 & 0.0 & 0.7 & 1.9 & 57 & 2 & 4 \\
\hline 9 & 2 & 5 & 32 & 213 & 2 & 208 & 218 & 3.5 & 0.1 & 2.8 & 4.9 & 62 & 2 & 3 \\
\hline 10 & 2 & 4 & 54 & 186 & 8 & 158 & 212 & 2.7 & 0.1 & 1.4 & 4.3 & 68 & 4 & 6 \\
\hline 11 & 3 & $\begin{array}{l}1 \\
0\end{array}$ & 42 & 672 & 61 & 580 & 723 & 10.2 & 0.7 & 7.2 & 14.5 & 66 & 8 & 12 \\
\hline
\end{tabular}

Table 3: Results of the measured cementum thickness $(C)$, incremental line thickness $(I L)$ and the estimated number of incremental lines $\left(n_{\mathrm{II}}\right)$ and their corresponding uncertainties, performed by a second 'reader' who took a second SEM-image (F2) of the corresponding samples (results of the limited Round Robin study)

Figure 3 shows the comparative measuring/counting results obtained from the reading of the two 'readers' from two SEM scans (F1 and F2) from the same sample in order to validate the procedure. From Figure 5 it is clear that the variation of nIL is within the range of the uncertainty, since the orange and green bars are close in value, meaning that the results from the two different 'readers' are practically identical. It is obvious that there is a negligible difference between $n_{\mathrm{IL}}$ uncertainties calculated from F1 and F2.

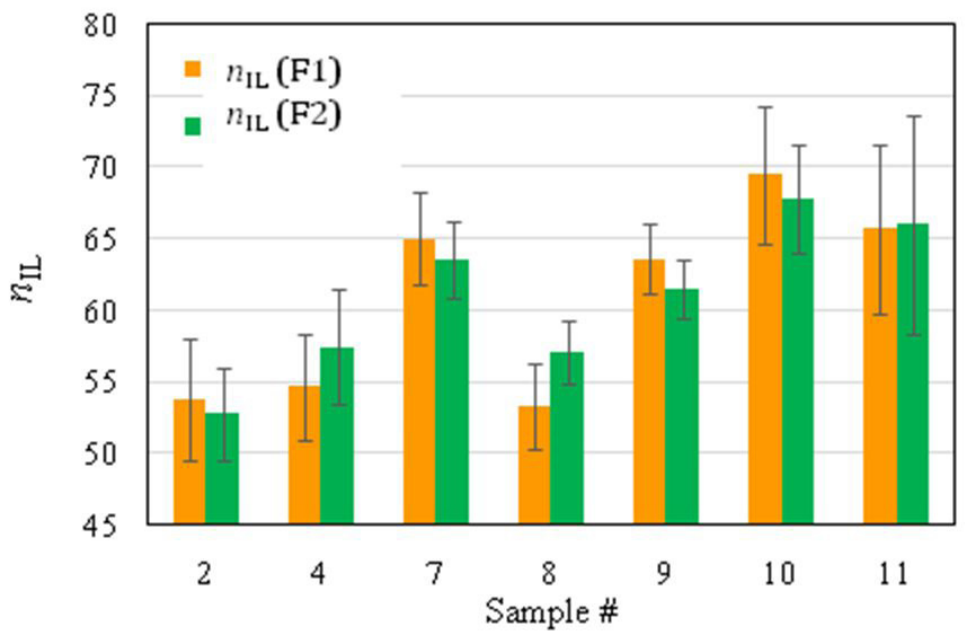

Figare 3: Estimated number of incremental lines $n_{\mathrm{IL}}$ calculated by two 'readers' from two different SEM-scans (F1 and F2) on the same sample (limited Round Robin study). The error bars present the standard combined uncertainty 
The relative combined uncertainties of nIL estimated by the first (F1) and second (F2) image 'reader' was in the range from 5\% to $9 \%$ and from $3 \%$ to $12 \%$, respectively. Hence, the accuracy of the measured values could be only related to the number of repeated measurements (cementum levels - $\mathrm{k}$ and number of readable array-elements within each level - N). As could be seen from (Figure 3 ), the uncertainty of $n_{\mathrm{IL}}$, established from the second 'reader' of the image (F2) of sample \#11 appears to be higher than that of F1, while as, for sample \#8 it appears to be lower. The latter suggests that the differences between the two readers could be ascribed to the errors from the random effect in the repeated measurements.

The results for the age estimations and the corresponding uncertainties are given in Table 4. The uncertainties of the tooth eruption were taken from column "Age of eruption- $T_{n}$ [28]" of Table 1. For instance, the value of the age of eruption for Sample \#3 according to Table 1 is $10.5 \pm 0.5 \mathrm{y}$, meaning that $T_{n}=10.5$, while as $u\left(T_{n}\right)=1$. Table 4 contains the uncertainty of the estimated age $\mathrm{u}(\mathrm{Te})$, which was calculated by means of combined standard uncertainty $u\left(T_{e}\right)$, using the uncertainties of $u\left(n_{\mathrm{IL}}\right)$ and $u\left(T_{n}\right)$.

\begin{tabular}{|c|c|c|c|c|c|c|}
\hline Sample \# & $\begin{array}{c}T_{n} \\
(\mathbf{y})\end{array}$ & $\begin{array}{c}u\left(T_{n}\right) \\
(\mathbf{y})\end{array}$ & $n_{I L}$ & $\boldsymbol{u}\left(\boldsymbol{n}_{I L}\right)$ & $T e(\mathbf{y})$ & $\begin{array}{c}u\left(T_{)}\right) \\
(\mathbf{y})\end{array}$ \\
\hline 1 & 9.5 & 1 & 49 & 2 & 60 & 2 \\
\hline 2 & 7.5 & 1 & 54 & 4 & 62 & 4 \\
\hline 3 & 10.5 & 1 & 51 & 3 & 62 & 3 \\
\hline 4 & 12.0 & 2 & 55 & 4 & 66 & 4 \\
\hline 5 & 11.5 & 1 & 44 & 2 & 57 & 2 \\
\hline 6 & 11.0 & 2 & 44 & 3 & 57 & 4 \\
\hline 7 & 9.5 & 1 & 65 & 3 & 74 & 3 \\
\hline 8 & 10.5 & 1 & 53 & 3 & 64 & 3 \\
\hline 9 & 9.5 & 1 & 64 & 2 & 72 & 2 \\
\hline 10 & 7.5 & 1 & 69 & 5 & 76 & 5 \\
\hline 11 & 9.5 & 1 & 66 & 6 & 74 & 7 \\
\hline
\end{tabular}

Table 4: $T_{n}, n_{I L}$, and $T_{e}$ along with their calculated uncertainties, $u\left(T_{n}\right)$ and $u\left(n_{I L}\right)$ and the combined uncertainty $u(T)$ for the 11 analyzed tooth samples

As could be seen in (Table 4), the calculated accuracy appeared to be within the range of the standard combined uncertainty, between 2 and 7 years.

\section{Discussion}

From our results, it also appeared that the periodontal disease does not affect the accuracy of the estimation since our sample collection \#1-11 contained 6 teeth affected by periodontal disease (comparison of the data from Table 1 and Table 4). Furthermore, the analysis of the variance in this study showed that the gender does not influence the estimated age, Te (also compare data of Table 1 with Table 4). Similar results were reported by other authors $[4,15,18,20,26]$.

In order to quantify the difference between the estimated $\left(T_{e}\right)$ and the real age $\left(T_{r}\right)$, we have introduced a relative bias, $(B)$, by means of relative deviation, as follows:

$$
\mathrm{B}=\frac{T_{r}-T_{e}}{T_{r}} \cdot 100 \%
$$

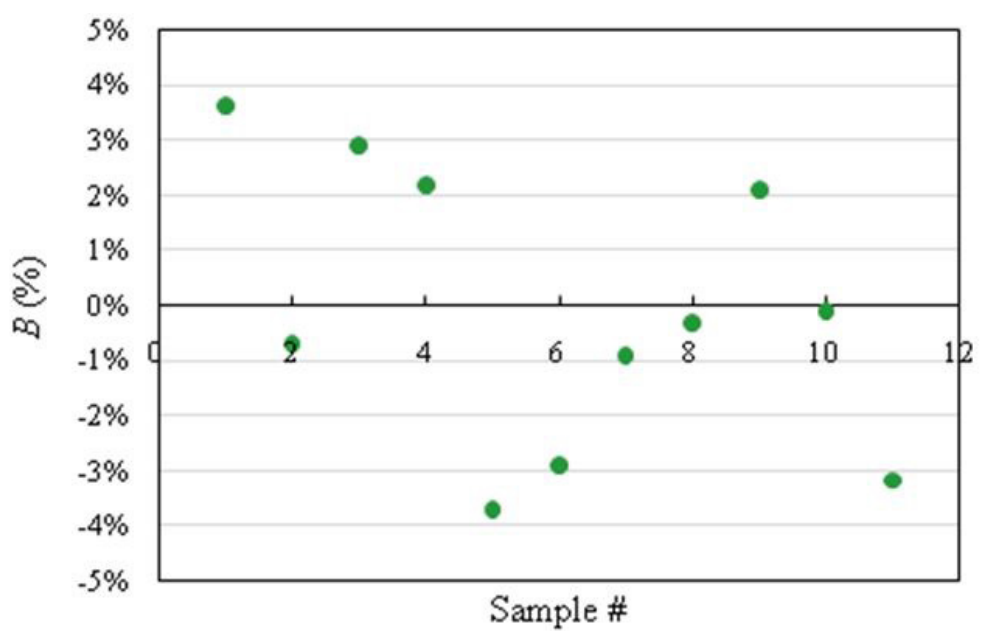

Figare 4: Relative bias (B) between $T_{e}$ and $T_{r}$ 
As could be seen in Figure 4, the values for the relative bias of the estimated age are in the range between $-4 \%$ to $+4 \%$. This relatively low range for the bias (B) makes the presented estimation method combined with the proposed protocol to be among the most accurate one. For the sake of comparison, we have also calculated the relative bias (B\%) of $T$ from $T$, using the data published by Aggarwal et al. [4]. The resulting values showed much higher bias, ranging from $-10 \%$ to $+23 \%$. Moreover, the relative deviation reported by Dias et al. [19] ranged between $-66.5 \%$ and $+35.5 \%$. The authors ascribed this uncertainty to the impact of the periodontal disease on the structure of the cementum. The relatively high deviations between the estimated $\left(T_{e}\right)$ and real age $\left(T_{r}\right)$ in several published studies were ascribed to the pathological degrading changes in the periodontal tissues (extensive periodontal disease) $[14,16-19,27]$. To the contrary, in our study, in which a limited number of incremental line arrays could be used in the age estimation, the periodontal disease did not influence the accuracy of this method, also reported by other authors [2-4]. It has been emphasized that the accuracy and repeatability of the method is independant on the tooth type or its location, systemic or periodontal health, but on the average which is obtained from as many counts as possible [3]. On the other hand, one has to take into account that the incremental lines are considered to be a qualitative indicator of changes in the environment and the metabolism parameters in the body.

Although it is based on small sample number, this protocol of age estimation $\left(T_{e}\right)$ from the incremental lines count $\left(n_{I L}\right)$, measurements of the cementum thickness $(C)$, and the average age of the corresponding tooth eruption $\left(T_{n}\right)$ using SEM images appears to be highly accurate. The relative bias $(B)$ between $T_{r}$ real age and the estimated age, $T_{e}$, was $+/-4 \%$. As a final conclusion, this method allows age estimation with one single SEM scan with high accuracy, regardless of the gender, health conditions of the tooth, even if only a limited number of arrays of distinct incremental lines are visible on the SEM image.

As to the SEM image of tooth \#8 from Figure 2, one can easily spot the occurrence of an anomalously thick incremental line indicating a "year" of a significantly higher mineralization, compared to other years in the individual's timeline. The calculations showed that the anomalous line is $23 \mathrm{rd}$ in the order of growth. If the age of eruption of this particular tooth \#14 is $10.5 \pm 0.5$ years, then the real age at which the anomalous line occurred, falls in the age range of 31-33. Due to a lucky circumstance, for this particular tooth donor, we possessed exclusive knowledge about the age of the only one childbirth - 32 (this female happened to be a mother of one of the coauthors of this study). Hence, this particular significantly thicker incremental line could be related to the metabolism of the 9 months long pregnancy. More profound studies in this direction are already in progress using 30 female tooth samples.

\section{Conclusions}

The proposed protocol (method) for age estimation offers highly accurate (95\%) tool, for estimation of the chronological age of an individual, using one single SEM scan. Application of this tool produces repeatable and reliable results. The relative bias (B) between real age $\left(T_{r}\right)$ and the estimated age $\left(T_{e}\right)$ was calculated to be $+/-4 \%$. Also, from a single case study, we report that an anomalously thick incremental line which occurred in Sample \#8 could be related to a childbirth of that female individual. This finding should be tested on a larger number of samples from female adult donors with a known history of childbirth. The method can serve forensic purposes.

\section{Acknowledgments}

We kindly express our thanks to Marijana Mircevska, MSc from the Faculty of Dentistry, European University in Skopje for the tooth sample collection.

\section{References}

1. Cardoza AR (2011) Forensic Dental Evidence (2nd Edn), An Investigator's Handbook, Chapter 4 - Forensic Dentistry Investigation Protocols, Elsevier, USA.

2. Kaur P, Astekar M, Singh J, Arora KS, Bhalla G (2015) Estimation of age based on tooth cementum annulations: A comparative study using light, polarized, and phase contrast microscopy. J Forensic Dent Sci 7: 215-21.

3. Gupta P, Kaur H, Shankari M, Jawanda MK, Sahi N (2014) Human Age Estimation from Tooth Cementum and Dentin. J Clin Diagn Res 8: ZC07-ZC10.

4. Aggarwal P, Saxena S, Bansal P (2008) Incremental lines in root cementum of human teeth: An approach to their role in age estimation using polarizing microscopy. Indian J Dent Res 19: 326-30.

5. Beloica D (2003) Decja stomatologija, Beograd: Elit-Medica.

6. Lieberman DE (1994) The Biological Basis for Seasonal Increments in Dental Cementum and Their Application to Archaeological Research. J Archaeo Sci 21: 525-39.

7. Berkovitz BKB, Holland RG, Maxham J (2009) Oral Anatomy, Histology, and Embryology (4th Edn) Elsevier, New York, USA.

8. Padavala S, Gheena S (2015) Estimation of Age Using Cementum Annulations. J Pharma Sci Res 7: 461-3.

9. Gustafson G (1950) Age determinations on teeth. J Am Dent Assoc 41: 45-54.

10. Scheffer VB (1950) Growth layers on the teeth of Pinnipedia as an indication of age. Nature 112: 309-11.

11. Laws RM (1952) A new method for age determination on mammals. Nature 169: 972-3.

12. Stott GG, Sis RF, Levy BM (1982) Cemental Annulations as an age criterion in forensic dentistry. J Dent Res 61: 814-7.

13. Meinl A, Huber CD, Tangl S, Gruber GM, Teschler-Nicola M, et al. (2008) Comparison of the validity of three dental methods for the estimation of age at death. Forensic Sci Int 178: 96-105. 
14. Charles DK, Condon K, Cheverud JM, Buikstra JE (1986) Cementum annulation and age determination in Homo sapiens. I. Tooth variability and observer error. Am J Phys Antropol 71: 311-20.

15. Wittwer-Backofen U, Gampe J, Vaupel JW (2004) Tooth cementum annulations for age estimation:results from a large known-age validation study. Am J Phys Anthropol 123: 119-29.

16. Kvaal SI, Solheim T (1995) Incremental lines in human dental cementum in relation to age. Eur J Oral Sci 103: 225-30.

17. Kagerer P, Grupe G (2001) Age-at-death diagnosis and determination of life-history parameters by incremental lines in human dental cementum as an identification aid. Forensic Sci Int 118: 75-82.

18. Bojarun R, Garmus A, Jankauskas R (2003) Microstructure of dental cementum and individual biological age estimation. Medicina (Kaunas) 39: 960-4.

19. Dias PE, Beaini TL, Melani RF (2010) Age estimation from dental cementum incremental lines and periodontal disease. J Forensic Odontostomatol 28: 13-21.

20. Pundir S, Susmita S, Pooja A, (2009) Estimation of age based on tooth cementum annulations using three different microscopic methods. J Forensic Dental Sci 1: 82-87.

21. Renz H, Radlanski RJ (2006) Incremental lines in root cementum of human teeth - A reliable age marker? Homo 57: 29-50.

22. Lipsinic FE, Paunovich E, Houston GD, Robison SF (1986) Correlation of age and incremental lines in the cementum of human teeth. J Forensic Sci 31 : 982-9.

23. Miller CS, Dove SB, Cottone JA (1988) Failure of use of cemental annulations in teeth to determinate age in humans. J Forensic Sci 33: 137-43.

24. Kierdorf H, Kierdorf U, Frölich K, Witzel C (2013) Lines of Evidence-Incremental Markings in Molar Cementum of Soay Sheep as Revealed by a Fluorochrome Labeling and Backscattered Electron Imaging Study, PLoS 8: 1-14.

25. Scheinfein MR, Unguris J, Kelley MH, Pierce DT, Celotta RJ (1990) Scanning electron microscopy with polarization analysis (SEMPA). Rev Sci Instrum 61: 2501-27.

26. Jankauskas R, Barakauskas S, Bojarun R (2001) Incremental lines of dental cementum in biological age estimation. Homo 52: 59-71.

27. Condon K, Charles DK, Cheverud JM, Buikstra JE (1986) Cementum annulations and age determination in Homo sapiens: II Estimates and accuracy. Am J Phys Anthropol 71: 321-30.

28. Biggerstaff RH (1977) Forensic dentistry and the human dentition in individual age estimation. Dent Clin North Am 21: 167-74.

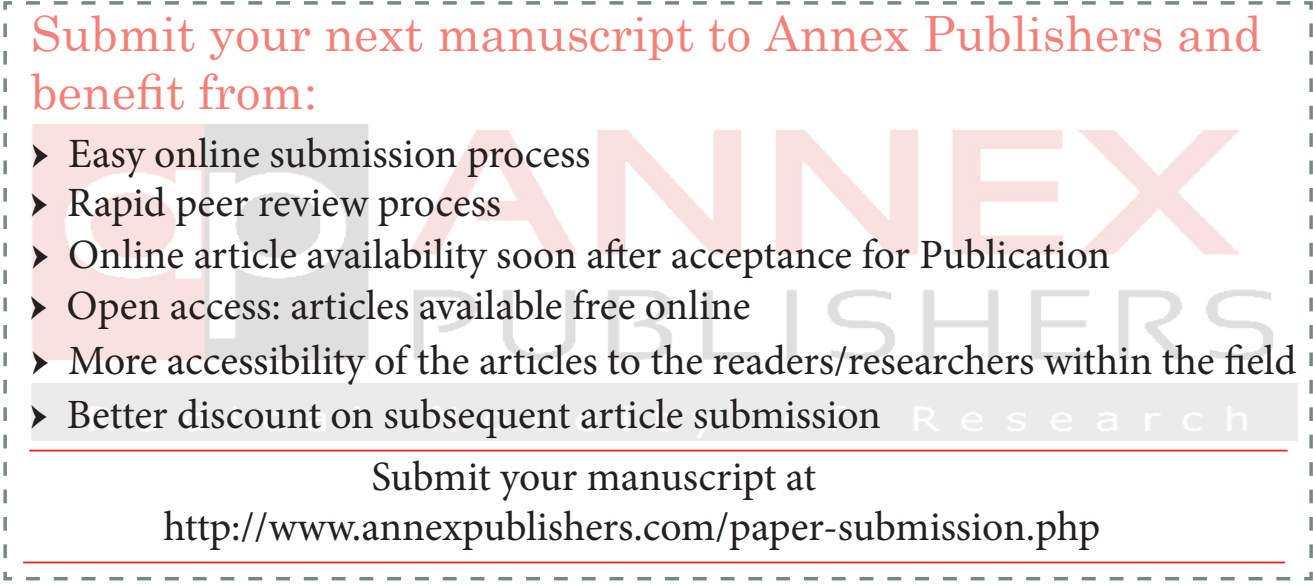

